\title{
RE-VISITING THE DECOLONISING OF SOUTH AFRICAN HIGHER EDUCATION QUESTION: A SYSTEMATIC LITERATURE REVIEW
}

\author{
V. Chikoko \\ Discipline of Educational Leadership, Management and Policy \\ University of KwaZulu-Natal \\ Durban, South Africa \\ e-mail: chikokov@ukzn.ac.za / https://orcid.org/0000-0001-6135-6172
}

\section{ABSTRACT}

During and soon after the \#feesmustfall and decolonisation student protests in South Africa, the decolonisation topic invaded the academic world in the country. There seems to exist a heterogeneity of viewpoints regarding what decolonising higher education entails. A search for systematic reviews on this topic did not yield any results. Such reviews can reveal what we currently know, what we do not know, and guide the knowledge production process going forward. This article analyses published research articles on decolonising higher education in South Africa through the lenses of soft reform, radical reform and "beyond-reform". Findings show that some papers dwell on decolonising isolated aspects of the university such as a programme or qualification, some on decolonising the entire university curriculum, and others on transforming the entire university. The article concludes that seeking to decolonise isolated aspects of the university constitute sub-soft reform strategies which leave the colonial pillars intact and therefore not contributing significantly to the decolonial project. Works that seek to decolonise the entire university curriculum are moving in the right direction towards radical reform, however, the article argues that to dismantle the colonial character of the present university requires the struggle to stretch beyond that. The South African university has a double-barrelled role to decolonise itself and to inform the societal decolonial project.

Key words: higher education, decolonising, coloniality, decoloniality, transformation, reform

\section{INTRODUCTION}

This article is a systematic review of studies on decolonising higher education in South Africa. The term "higher education" in this case refers to university education. To be relevant locally and internationally, and to be competitive and equal global players, universities need to transform their modes of knowledge production, content, nature of knowledge systems as well as seek partnerships to steer the needed change. The decolonisation question has invaded the South African academic world (Martinez-Vargas 2020). During and after the 2015 \#fees must fall and decolonising higher education student protests in South Africa, there was a discernible heightened interest among South African academics and researchers to debate and write about 
the decolonisation part of that movement. Journals called for papers on the subject, with some dedicating special issues in that regard. According to Zembylas (2018), if decolonising discourses are taken at face value, there lies a danger that they may end up being empty rhetoric. There appears to exist quite a heterogeneity of viewpoints regarding what decolonising higher education entails. A literature search yielded no evidence of systematic reviews of research on decolonising higher education in South Africa. Systematic reviews help us to capture what we know, what we think we know, and what we do not know yet (Hallinger 2018) about an issue. Thus, this article addressed the following questions:

1. What issues about decolonising higher education do the journal articles tackle?

2. How do the researchers understand the notion of decolonising higher education?

3. What lessons can we draw from the studies regarding what decolonising higher education should entail?

The rationale for conducting this review of studies on decolonising higher education in South Africa is grounded in the belief that common understandings of this subject in the country are necessary given not only the interconnectedness of the higher education institutions in question, but also how they impact on and are in turn impacted upon by society.

This article unfolds through four main sections. First, a conceptual framework is given. Second, the method followed is explained. Third, results are presented. Fourth, a discussion of the results is done. The article folds with concluding remarks.

Readers would normally expect that because the term "decolonisation" is at the centre of this article, the author should problematise it from the outset. I elected to adopt a different approach. Because one of the critical questions I seek to have addressed by the end of the article namely, how the researchers understand the notion of decolonising higher education (see question 2 above), I have deferred this matter until after presenting the researchers' perspectives.

\section{CONCEPTUAL FRAMEWORK}

Zembylas (2018) identifies three types of reform decolonisation of higher education may assume. First is soft reform. This relates to increasing access, implementing inclusionary measures and supplementing existing curricula with non-Western perspectives. This type of reform makes no challenge to existing power relations and structures (Stein and Andreotti 2017). The reform adopts an additive approach. The result, Zembylas argues, is continued dominance of the Eurocentric culture. 
Second is radical reform. This entails a rejection of the colonisers' values, norms and worldviews. It involves empowering the marginalised such as changing institutional structures, and redistributing material and other resources. I am aware and would accept a possible criticism that the notion of empowering the marginalised suggests that these people are helpless and at the mercy of those with power to emancipate them which in essence would be contradictory to the decolonisation agenda. However, it is my view that dismantling the colonial legacies requires a two-fold approach: the historically marginalised taking it upon themselves to change the status quo; and the historically powerful not only accepting change but actively participating in the transformation journey. Vorster and Quin (2017) argue that for South Africa, this would entail changing structures and practices of administration and leadership, research, scholarship, curricula, pedagogy, etc. This may include developing and running leadership development programmes for young academics, according them opportunities to exercise such leadership, and incentivising indigenous research and scholarship.

Third is what Zembylas refers to as "beyond-reform". This form is based on the thinking that the modern existence of higher education institutions depends on colonisation and racialisation for its continuation. Therefore, there are limits to which transformation is possible, within higher education as we know it (Vorster and Quin 2017). As I see it, "beyond -reform" would also mean that as a university engages in transformation, it must be careful not to throw away the baby with the bath water. This calls for sober approaches involving accepting those values from the colonial past which work and rejecting unworkable local approaches.

The article adopts this framework in analysing the selected research articles.

\section{METHOD}

The aim of the systematic review was to determine the "dominant features of the terrain" (Hallinger and Bryant 2013) in terms of the studies' "stories" about what decolonising higher education entails. Therefore, I adopted a topographical review (Hallinger 2018). Such reviews focus on unearthing patterns of the knowledge produced as well as summarising conceptual and trends in methodologies applied. They also help to point at possible future research foci (Hallinger 2013; Hallinger and Bryant 2013). Thus, this review offers some insights on how researchers understand the notion of decolonising higher education and what such characterisations may entail moving forward in intellectualising this topic.

\section{Identification of sources}

The goal was to analyse English-language research articles published in peer-reviewed journals within a 10-year timeframe, 2010-2020. This period was appropriate in three main ways. First, 
it included the period of the publication boom in the topic, following the \# fees must fall and decolonising higher education movements in 2015. Second, it included a period of five years before the said boom, thus allowing for research evidence unduly influenced by the student protests. Third, it is a long-enough period to provide a stable trajectory of research trends about this subject area. The journals had to be in the lists of the South African Department of Higher Education and Training (DHET) accredited platforms. Google Scholar was the main search tool. Through an iterative process of Google Scholar searches, the following key search terms were used: decolonising education; decolonising higher education; decoloniality; transformation; university transformation, South African higher education; colonialism; and colonisation. When a source was deemed relevant, the pdf file was downloaded including all the citation information.

The search yielded 35 sources. These included some that did not meet the target timeframe and others whose foci were outside higher education, specifically university education. Through further filtration, 12 sources were arrived at for the study.

\section{Data extraction}

A spreadsheet was set up to store data. Extracted data included the author(s), article title, journal, year of publication, type of paper (empirical, theoretical), research method, and topic (Hallinger 2018). Detailed notes were compiled about the main content of each paper.

\section{Data analysis}

Qualitative data analysis was adopted. First, this involved reading and re-reading both the main source and the compiled notes about each paper. Second, analysis entailed seeking answers from each article, to each of the research questions identified above. Third, analysis proceeded into the writing, through summarising the essence of each article. Fourth and final, the summary of each article was examined through the lenses of the conceptual framework of the study and placed into one or more categories namely, soft reform, radical reform, and "beyond reform".

\section{RESULTS}

This section presents summaries of each of the 12 research articles. The presentation does not categorise the works in any way. Instead, summaries are simply presented according to when they were completed in the process of preparing this article, thus allowing every paper to "speak" before any judgement is made on it. The categorisation is done in the discussion section of the article.

In a study in one South African higher education institution, Mampane, Omidire and 
Aluko (2018) researched the perspectives of students from different nationalities across Africa about what decolonisation would entail. They adopted a questionnaire, interviews and focus group discussions as data collection instruments. These researchers report that in South Africa students are the ones who "forced" researchers and institutions to put the decolonisation question on the agenda. Similarly, Le Grange (2016) wrote that students feel disconnected from the higher education system.

They found that their participants viewed decolonisation as the addressing of past injustices and marginalisation. It meant the valuing of indigenous languages and culture in the curriculum. The researchers argue that language is crucial in knowledge production. The imposition of language is the imposition of culture (Higgs 2012). The researchers conclude that what is required are what they call glocal initiatives that is including elements of the global and local in the curriculum. They echo Winfield (2017) who saw decolonisation of higher education as entailing developing curricula that build on the best knowledge, skills, and values from around the world.

Sathorar and Geduld (2018) wrote about decolonising teacher education in the context of a South African Faculty of Education. Among other objectives, their study sought to establish what decolonisation is and what decolonising the curriculum entails. They concede two things: that the recent students' protests in the country about decolonisation drove their research, and that their work on decolonisation in higher education was in its early stage.

They adopted a participatory action research method involving a three-year long critical dialogue with students and staff. They focused on Education theory and Teaching Practice modules. The researchers report that in their Faculty, a decolonised curriculum is defined as one that recognises and prepares student teachers to work in different contextual realities, considering issues of privilege, inequality, poverty, unemployment, demographic underrepresentation and racism. They indicate that this perspective derives from Tamburro's (2013) conceptualisation of the same.

Their findings reveal that a decolonised curriculum must include local context and content. It entails taking local context into account when presenting lectures, and connecting theory to practice. They say decolonising teacher education should be embedded in a critical approach aimed at creating counter hegemonic intellectual spaces in which new worldviews can unfold.

Through semi-structured interviews, Pillay and Swanepoel (2018) explored lecturers' experience of decolonising the BEd Honours curriculum at a South African university. They aimed at establishing how a lecturers' writing programme for the Honours curriculum reform transformed their perceptions about their own practice during a process of decolonising the curriculum, what influence power and personal knowledge had during the process, and what 
challenges lecturers encountered. These researchers also confirmed that the recent students' protests motivated the study.

They found that Western worldviews were systemically rooted in the curriculum. This restrained emancipation efforts. Lecturers lacked the means to engage with a solely Afrocentric theoretical base. There was need for collaboration and self-empowerment in order to deconstruct power. Decolonising the curriculum would require combining indigenous theories with those from other parts of the world. There was also need to involve school teachers and tertiary students in shaping the curriculum. Overall, they think that decolonising the curriculum requires tapping into indigenous knowledge systems and expanding the knowledge base.

Constandius et al. (2018) studied a South African university's students and lecturers' reactions to the \#feesmustfall and decolonising the curriculum protests. Their aim was to explore evidence of decolonisation and social justice within teaching and learning in different faculties and departments. They administered a questionnaire to lecturers. They observed a lecturers' one-day workshop on decolonisation and social justice. They also held a discussion group with lecturers. They sent photographs of protests to students and lecturers for comments.

They report that there was evidence of polarisation among stakeholders in the university. There was need to define decolonisation, to foster openness and to promote African centrality in teaching and learning. The institution needed to invest in transitional engagement among stakeholders. University space such as symbols, offices, buildings, architecture, artefacts, photographs and statues needed to be decolonised (even if they report the need for investing in defining the term "decolonising". The use of social justice in teaching and learning was identified as an important starting point for decolonisation.

In an article entitled "\#Rhodes must fall, a post humanist orientation to decolonising higher education institutions", Murris (2016) writes about a particular event that resulted in a series of others. It was the smearing by student Chumani Maxwele, of human excrement on the statue of British colonialist Cecil Rhodes at the University of Cape Town. This event triggered further action including the occupation of buildings, the Rhodes must fall movement, and the call for the decolonisation of the university.

Murris took and analysed photos of the events. Some photos were of the statue during the time of its removal. Others were of a Fine Arts student Sethembile Msezane who on the afternoon the Rhodes statue was removed, "became" a statue by balancing on a plinth for four hours.

Out of that work, Murris argues that the core challenge for the Rhodes must fall movement and the decolonisation of higher education is not to concentrate on negative differences such as black-white, and male-female. To Murris decolonising a university is not only an 
epistemological question it is also ontological. The decolonising question can remain radically open if people view meaning making as discursive.

Mahabeer (2018) writes about curriculum decision-makers on decolonising the teacher education curriculum. She interviewed some of those who had been involved in the National Teacher Education Curriculum Policy Framework in South Africa. The focus was on participants' personal experiences, philosophies and thoughts on decolonising the curriculum.

She found that some were happy with the status quo while others called for what they referred to as an indigenous curriculum. Some wanted to see a mediation of the old and the new to create a well-rounded, global teacher. Yet others felt that there was no deep enough understanding of what the term curriculum really meant. Others expressed indecision. The overall sentiment was that the decolonised curriculum should make better human beings. It should adopt a re-humanising approach.

Through exploring decolonial literature, Martinez-Vargas (2020) writes on decolonising higher education research and advocates a shift from a university to a pluri-versity (a plurality) of approaches. The author preludes the paper by signalling that the challenging times in which we currently live regarding developments in higher education show that it is time for change. Martinez-Vargas says in a pluri-versity practices should be diverse in form and content including knowledge systems historically excluded, but also equally preserving those that, although imposed, should still form part of an ecology of knowledges.

Martinez-Vargas advocates the use of indigenous methodologies to decolonise research. To achieve that, there is need for greater use of participatory research methodologies that involve local communities, both as participants and knowledge holders, taking into consideration cultures, beliefs and values (Dei 2014). To this author, decolonisation should not only promote curriculum changes, but also consider the Eurocentric onto-epistemology of higher education institutions. The latter institutions, Martinez-Vargas argues, are currently in contradiction with the cultural capital students bring. This leads to huge problems such as educational failure, emotional distress and identity crises.

Higher education research must embrace the diversity of worldviews around the world, in Africa and South Africa. To Martinez-Vargas, despite the importance of the indigenous movement, it should not jeopardise other decolonial approaches such as the LGBTQI hence the pluri-versity, a plurality of subjectivities-African, feminist, indigenous, LGBTQI, etc. Both Western and previously excluded epistemic systems need to be critically analysed. To do so, there is need for democratic academic spaces. All knowledge systems are incomplete. This incompleteness forces an epistemic dialogue between all. Plurality is not about changing one hegemonic system for another but promoting diversity and plural knowledges. 
In a theoretical paper involving an analysis of the transformation that has taken place in South African higher education thus far, Ramrathan (2016) writes about shifting higher education transformation beyond counting the numbers, into curriculum spaces. He argues that deep curriculum transformation in higher education is possible if there is a shift from predominantly number counting to curriculum intellectualisation. To him, numerical changes including widening access, changes in programme enrolment patterns, resources and programme differentiation and interventions such as identification, monitoring, supporting and tracking at-risk students and financial support have occurred and continue to do so, however, fundamental higher education curriculum intellectualisation has not happened.

According to Ramrathan, the transformation focus should be on an ontological rather than responsive orientation. He shares Apple (2010)'s view that relationships between power and curriculum construction should be continually illuminated, disrupted and recorded in order to propel change on a continual basis.

Writing about decolonising the university curriculum Le Grange (2016) indicates that the 2015 students' protests precipitated renewed attention towards the decolonisation of the university. He identifies the focus of his paper as one of seeking to add to the conversation on decolonising the university curriculum specifically around what decolonisation is, why it is necessary, the importance of re-thinking how the curriculum is conceived and possible ways of decolonising the curriculum.

On what decolonising the curriculum is, Le Grange refers to Chilisa's (2012) five phases thereof. The first relates to re-discovery and recovery. In this phase, the colonised re-discover and recover their own history, culture, language and identity. The second is "moving". This involves a process of lamenting the continued assault on one's culture and identity. The third is "dreaming". This relates to theorising and imagining alternatives. The fourth is "commitment". This involves voicing out what one perceives and desires. Fifth and final is "Action" where people adopt strategies for transformation.

Le Grange argues that transforming the university curriculum is a microcosm and impetus for broader societal transformation. Such transformation has a number of elements. He refers to Smith (1999) who identifies seven elements. First is deconstruction and reconstruction. This entails discarding what has been distorted including the deficit models, and re-telling. Second, self-determination and social justice. This entails seeking legitimacy for knowledge embedded in own histories and experience. Third, ethics. This is about institutionalising indigenous knowledge systems. Fourth, language. This is about teaching and learning in indigenous languages. Fifth, internationalisation. This is when international scholars share common experiences, issues and struggles. Sixth, history. This involves studying the past in order to 
recover the lost culture including language. Seventh, critique. This is about doing a critical appraisal of the colonial model that is currently hindering change.

To Le Grange, decolonising the curriculum should be based on 4Rs. Relational accountability is when all parts of the curriculum are connected and the curriculum is accountable to all relations-human and the more-than-human. Respectful representation is about creating space for voices and knowledges of individual people. Reciprocal appropriation relates to ensuring that both the community and university share the benefits of knowledge produced and disseminated. Finally, rights and regulation is about according ownership of knowledge to the indigenous people where appropriate.

In a theoretical paper, also motivated by the \#Rhodes must fall movement, Francis and Hardman (2018) write about using social media to decolonise learning spaces in South African higher education institutions. The aim of the paper was to look at the potential for higher education institutions to adopt social media to facilitate the decolonisation of South African universities. Francis and Hardman see social media as having potential to disrupt traditional power relations in the academy. In the process, this would give students the voice they previously did not have. They argue that learning is not an individual process, rather it is socially and culturally-situated. They see a need for the development of theory that explains the learning that takes place when learning with technology.

Francis and Hardman argue that social media can create inclusive transcultural learning spaces. These would allow students to participate in learning as equals. They say through social media, students and teachers interact on a level playing field, thus destroying the traditional student-teacher binary. To them this is an important step for understanding the multiple perspectives around decolonising South African universities. Social media exposes learners and other users to new epistemologies and experiences. These authors assert that in their communication around Rhodes must fall, students adopted social media and they chose that approach for a reason. Thus, they conclude it is time to exploit that medium.

In a theoretical paper, Fomunyan (2017) writes about decolonising the future in what he refers to as the untransformed present South African higher education. In the paper, one question he seeks to address relates to what should be decolonised to ensure transformation of the present and future. To Fomunyan, the aim of decolonising higher education should be to create a unique, contextual higher education system grounded in African values, beliefs and experiences anchored on indigenous knowledge. It is about shifting the balance of power in relation to knowledge hegemony and the knowledge economy.

Fomunyan identifies three forms of higher education decolonisation. First is a partial or complete makeover of the institutional architecture. This involves both human and material 
changes. Human-wise it entails making the university a safe place for all. It involves removing institutional racism and laying bare historical failures such as patriarchy thus, bringing about a sense of belonging to all. Material-wise it is about rebranding such as changing colonial names, buildings and public spaces. Second is curriculum divergence and convergence. This he says involves breaking away from Eurocentric curricula and including local content and experiences. Fomunyan further identifies three ways of conceptualising the term "curriculum". There is the hidden curriculum - the unspoken and yet institutionalised. Because of its hidden power, it is a gatekeeper. Therefore, it is curriculum as reproduction. There is also curriculum as consumption. This relates to focussing on what is required out there in the world, untransformed as it may be. Lastly, there is curriculum as transformation. This is engaging, relevant, contextual and legitimate knowledge. The third form Fomunyan identifies relates to democratising university hegemony. This he argues involves taking African experiences and perspectives to the rest of the world.

Zembylas (2018) wrote about decolonial possibilities in South African higher education, in particular, what the links between humanisation and the decolonisation of higher education are and what this implies for pedagogical praxis. The author argues that while there are increasing efforts to explore what decolonising higher education curricula means, there has been less theorisation regarding what it might imply for higher education pedagogy and praxis.

Drawing from Stein and Andreotti (2017), Zembylas suggests that decolonisation is a broad term for diverse attempts at resisting the distinct but interwoven processes of colonisation and racialisation. It is an umbrella term for efforts to transform and redress historical injustices and to create and activate modes of knowing, being and relating that colonisation and racialisation processes seek to eradicate.

Zembylas distinguishes between colonialism and coloniality. To the author, the former refers to a temporal period of oppression that has come and gone while the latter denotes a continuity of colonial forms of domination after the end of the former. Zembylas sees decolonisation as efforts tied to the historical period that was fought and defeated, although to some degree it is also an ongoing process, while decoloniality refers to efforts to challenge coloniality.

Zembylas argues that decolonial theory shows that the struggle for global social justice is inseparable from that for cognitive justice. The latter refers to recognition for epistemic diversity (Fricker 2007). Drawing from Mbembe (2016), Zembylas views decolonising knowledge as collective, systematic and systemic processes undoing cognitive injustices including methods of teaching and assessment, content, research, publishing norms, etc.

Zembylas' position is that humanising pedagogy is decolonising pedagogy. The author 
sees humanisation as a process of becoming more fully human through self-actualisation. Zembylas indicates that humanising pedagogy derives largely from Paulo Freire's work that advocates students and educators in mutual humanisation through problem-posing and dialogue. Zembylas suggests two ways higher education can bring about humanising pedagogy. One is to draw from various theoretical frameworks such as critical race theory, Black feminist theory, etc in order to re-construct knowledge from non-Eurocentric perspectives. Another is for South African higher education to interrogate the pedagogical practices characterising Eurocentric knowledge approaches by drawing on and appropriately twisting these very practices.

\section{DISCUSSION}

The subject of decolonisation is not new in South African literature (see for example Alexander 2002) and in Africa (see for example, Nyamnjoh 2012; Mbembe 2001; Mamdani 1996). That said it is noteworthy that all the 12 papers reviewed in this paper were published between 2016 and 2020. Half of the 12 papers were published in 2018. By any standards, this is a literature boom. Many of the authors indicated that their work was precipitated by the 2015 student protests in the country. Even those that do not say so upfront, the work suggests the same. It is understandable and to be expected that researchers respond to the goings-on in their work environments and around them in order to create and share knowledge. However, it also seems that researchers, in a reactive manner "hijacked" the student protests movement and made the decolonisation subject their own. There are questions as to whether such momentum is sustainable after the specific events in question. Now that student protests around decolonisation have died down, at least for now, what likelihood is there that we will continue to see growth in scholarship on that subject, or is the South African university now decolonised? I think the decoloniality project is far from complete, however, whether or not decolonising the university was a bona fide agenda item on the protesting students' list is a matter for another day. This brings us to what it is that the papers focused on.

The papers reflect a wide range of focus areas. One relates to seeking to establish what the term decolonisation means. A second is about interrogating the decolonising of the curriculum in its broad sense. Third, the decolonising of a specific constituency of the university curriculum namely teacher education. Fourth, decolonising a specific programme (BEd Honours). Fifth, seeking evidence of decolonisation within teaching and learning across departments and faculties. Sixth, decolonising research. Seventh, seeking to understand personal experiences and philosophies about decolonisation. Eighth, ways to decolonise. Ninth and tenth, studying and interpreting particular events. Tenth, what implications decolonisation 
would have on pedagogy and praxis, and twelfth, decolonising the university in its entirety. A critical look at these focus areas raises questions as to whether or not some of what the researchers positioned for decolonisation can be decolonised as stand-alone areas. When superficial efforts at curriculum change are made, authentic decolonial efforts fail (Nyoni 2019). To seek for answers to the question, it is necessary to visit the decolonisation literature.

Of interest is the literature coming out of Zembylas' (2018) work, distinguishing between colonialism and coloniality, and between decolonisation and decoloniality. Coloniality is the state of continued domination (Maldonado-Torres 2011) of the culture of the coloniser after colonialism per se has ended. The war and battles of seeking to change this status quo are what is meant by decoloniality. It seems logical therefore that we should be talking about decolonialising in place of decolonising. However, it does seem that the latter term has gained far more traction than the former. Thus, the understanding of the studies presented in this paper is that authors are using the term "decolonising" to refer to efforts to fight and defeat coloniality. Higher education institutions are complicit in the continuation of this domination as they are in support of what the author refers to as scientific racism. In a context where Western knowledge is systemically privileged over the non-Western (Higgs 2016; Mamdani 1996; Mangcu 2016), how viable would it be to seek to decolonise an aspect of a systemically dominated institution, such as its teacher education curriculum? In my view, such efforts are consistent with soft reform in that the pillars of coloniality remain. In fact, I would call the efforts, sub-soft. It is attempting to transform one sub-set of an untransformed whole. Similarly, if South African higher education remains in support of scientific racism, which I argue it does, seeking to decolonise research therein may also not succeed because the colonial fundamentals remain intact.

As I see it, decolonising the university curriculum in its entirety-the manifest, the hidden and the transformational (Fomunyan 2017) as some of the papers advocate (Constandius et al. 2018; Zembylas 2018; Le Grange 2016; Ramrathan 2016), is an important move in the direction towards what Zembylas (2018) refers to as radical reform. It is a move beyond what Ramrathan (2016) refers to as number counting. Decolonisation in higher education is not only a process of gaining institutional and political independence. It must involve the imperative of intellectual and academic self-determination as well as the contextualisation of knowledge, research, teaching and learning (Kindiki et al. 2019). As Mampane et al. (2018), drawing from Winfield (2017) say, there is need for curricula that build on the best knowledge, skills and values from around the world. However, while the curriculum is the mainstay of what a university stands for, I argue that a university is broader than its curriculum. This brings to question whether a university's curriculum can be successfully decolonised without dismantling the pillars that 
brought about the university in the first place. This brings me to the question of decolonising the university in its entirety.

Given the entrenched current colonial character of South African universities, papers I reviewed here that advocate the decolonisation of the university (Fomunyan 2017; Mampane et al. 2018; Zembylas 2018; Le Grange 2016; Murris 2016) seem to be consistent with the notion of radical reform. As Glissant (1997) rightly argues, the project of decoloniality must be thought of in terms of knowledge, power, becoming and affect. It is about a relation of equality with and respect for the other as different but not inferior. This suggests a need for psychic decolonisation, among other things. A combination of cultural competency and cultural humility is required (Nazar et al. 2015). The former entails the acquisition of fact and general knowledge about the other person. The latter refers to a self-reflective process, which challenges existing power imbalances in interactions, in this case in higher education institutions. It is about developing awareness of one's own and others' cultural beliefs and practices. It is about developing critical consciousness necessary for cultural diversity to thrive. Thus, the university decoloniality project is about overhauling the curriculum, pedagogy, access, policy, process, experience, outcomes, subjectivities, racialisation and racism (Tate and Bagguley 2017). But can the university successfully win the decoloniality battle in a society still suffering coloniality? This is not likely to succeed. This brings me to the last type of reform in the conceptual framework namely "beyond-reform".

I subscribe to Vorster and Quin's (2017) contention that there are limits to which transformation is possible within higher education as we know it today. As Fricker (2007) rightly argues, the struggle is for social justice. Fricker argues further that such struggle is inseparable from that for cognitive justice. The latter should form the backbone of decolonising the university. Ngugi (2004) sees decolonisation as involving a decisive rejection of the centrality of the West in Africa's understanding of itself and its role in the world. It is about centring ourselves intellectually and culturally (Prinsloo 2016). Against this background, I wish to present two intertwined arguments here. First, the university, situated in a colonial society as it does, cannot fully decolonise. Second, the university cannot sit back and wait for society to decolonise instead it must be society's major instrument in the struggle for decoloniality. The university must therefore play a double-barrelled role of transforming itself and informing society at large on how to do so. This will take what Nyoni (2019) refers to as the de-caging of the colonised mind through a process of shifting away from Western perspectives as the centre for development. To illustrate, in seeking to transform itself the South African university must move from mere rhetoric regarding the upgrading of indigenous languages towards developing them as complimentary media of instruction. Language is the quintessence of humanity. In 
many sectors such as banks, post offices, wholesale and retail shops, some workers therein cannot speak languages spoken by the majority of people in the area. Therefore, a big chunk of customers often get disadvantaged. The university is well placed to partner with other organisations and change this situation by offering short practical courses such as language teaching.

\section{CONCLUSION}

This article set out to do a critical look at published research articles on the decolonising of South African higher education. The apparent heterogeneity of viewpoints about what decolonising higher education entails, ranging from transforming a single qualification all the way to the entire university, motivated the article. The article has unfolded through four main sections: the conceptual framework, method, results, and discussion. The article put to scrutiny 12 research articles through the lenses of soft reform, radical reform and "beyond-reform". The results show that some papers focus on decolonising specific sectors of the university such as teacher education, a qualification, or research. Others focus on broader issues such as decolonising the curriculum or the entire university. It has emerged that the issue at hand is the decoloniality of higher education. The article has argued that focusing on decolonising single aspects of the university are sub-soft reforms because they are incapable of breaking the pillars of coloniality. While those that target decolonising the entire university curriculum are on the right track towards radical reform, however, the university is broader than its curriculum. Those that target the entire university are "on the money" regarding radical reform. However, the university cannot fully decolonise if society remains in colonial mode. The university must play a dual, concurrent role of decolonising itself and informing the societal decoloniality project.

\section{REFERENCES}

Alexander, Neville. 2002. An ordinary country: Issues in the transition from apartheid to democracy in South Africa. Scottsville: University of Natal Press.

Apple, M. W. 2010. Keynote address at the World Congress for Comparative Education Society, XIV World Congress, Istanbul - Turkey, June 14-18.

Chilisa, Bagele. 2012. Indigenous research methodologies. Los Angeles: Sage publications.

Constandius, E., I. Nell, N. Alexander, M. Mckay, M. Blackie, R. Malgas, and E. Setati. 2018. "\#FeesMustFall and decolonising the curriculum: Stellenbosch University students' and lecturers' reactions." South African Journal of Higher Education 32(2): 65-85.

Dei, G. J. S. 2014. Indigenizing the school curriculum: The case of the African university. https://researchgate.net/publication/288399311_indigenizing the_school_curriculum the case of_the_African_university (Accessed 16 September 2020).

Fomunyan, K. George. 2017. "Decolonising the future in the untransformed present in South African higher education." Perspectives in Education 35(2): 168-180. 
Francis, S. and J. Hardman. 2018. “\#Rhodesmustfall: Using social media to 'decolonise' learning spaces for South African higher education institutions: A cultural historical activity theory approach." South African Journal of Higher Education 32(4): 66-80.

Fricker, Miranda. 2007. Epistemic injustice: Power and the ethics of knowing. Oxford: Oxford University Press.

Glissant, Edouard. 1977. Poetics of Relation. Translated by Betsy Wing. Anne Arbour. MI: Michigan: University of Michigan Press.

Hallinger, Philip, and Darren A. Bryant, 2013. "Accelerating knowledge production on educational leadership and management in East Asia: A strategic analysis." School Leadership and Management 33(3): 202-223.

Hallinger, Philip. 2013. "A conceptual framework for reviews of research in educational leadership and management." Journal of Educational Administration 5(12): 126-149.

Hallinger, Philip. 2018. "Surfacing a hidden literature: A systematic review of research on educational leadership and management in Africa." Emal 46(3): 362-384.

Higgs, F. 2012. "The African renaissance and the transformation of the higher education curriculum in South Africa." Africa Education Review 13(1): 87-101.

Kindiki, Jonah N., Malve von Möllendorff, Karsten Speck, and Paul Webb. 2019. "African-German Cooperation towards Decolonising Higher Education: CERM-ESA Approaches and Lessons Learnt." ZEP: Zeitschrift für Internationale Bildungsforschung und Entwicklungspädagogik 42(2): 11-15.

Le Grange, L. 2016. "Decolonising the university curriculum: Leading article." South African Journal of Higher Education 30(2): 1-12.

Mahabeer, Pryah. 2018. "Curriculum decision-makers on decolonising the teacher education curriculum." South African Journal of Education 38(4). https://doi.org/10.15700/saje.v38n4a1705 (Accessed 14 September 2020).

Maldonado-Torres, Nelson. 2011. "Thinking through the decolonial turn: Post continental interventions in theory, philosophy, and critique-An introduction." Transmodernity: Journal of Peripheral Cultural Production of the Luso-Hispanic World 1(2): 1-14.

Mamdani, Mahmood. 1996. Citizen and subject: Contemporary Africa and the legacy of late colonialism. Princeton, NJ: Princeton University Press.

Mampane, Ruth M., Margaret F. Omidire, and Folake R. Aluko. 2018. "Decolonising higher education in Africa: Arriving at a global solution." South African Journal of Education 38(4). https://doi.org// 10.15700/saje.v38n4a1636 (Accessed 15 September 2020).

Mangcu, Xolela. 2016. "Decolonising South African sociology: Building on a shared 'text of blackness'. Du Bois Review." Social Science Research on Race 13(1): 45-59.

Martinez-Vargas, Carmen. 2020. "Decolonising higher education research: From a uni-versity to a pluriversity of approaches." South African Journal of Higher Education 34(2): 112-128.

Mbembe, Archille J. 2016. "Decolonizing the university: New directions." Arts and Humanities in Higher Education 15(1): 29-45.

Mbembe, Archille J. 2001. On the postcolony. Berkley, CA: University of California Press.

Nazar, Mahdi, Kathleen Kendall, Lawrence Day and Hamde Nazar. 2015. "Decolonising medical curricula through diversity education: Lessons from students." Medical Teacher 37(4): 385-393.

Ngugi, wa Thiong'o. 2004. Decolonising the mind. The politics of language in Africa Literature. Nairobi: East African Educational Publishers Ltd.

Nyamnjoh, Francis B. 2012. "Potted plants in greenhouses: A critical reflection of the resilience of colonial education in Africa." Journal of Asian and African Studies 47(2): 129-154.

Nyoni, Jabulani. 2019. "Decolonising the higher education curriculum: An analysis of African intellectual readiness to break the chains of a colonial caged mentality." Transformation in Higher 
Education 4(1):1-10.

Pillay, Preya, and Eben Swanepoel. 2018. "An exploration of higher education teachers' experience of decolonising the Bachelor of Education honours curriculum at a South African university." Perspectives in Education 36(2): 119-131.

Prinsloo, Estelle H. 2016. "The role of the humanities in decolonising the academy." Arts and Humanities in Higher Education 15(1): 164-168.

Ramrathan, Labby. 2016. "Beyond counting the numbers: Shifting higher education transformation into curriculum spaces." Transformation in Higher Education 1(1): 1-8.

Sathorar, Heloise and Deidre Geduld. 2018. "Towards decolonising teacher education: Reimagining the relationship between theory and praxis." South African Journal of Education 38(4). https://doi.org//10.15700/saje.v38n4a1714 (Accessed 18 September 2020).

Smith, L. 1999. Decolonising methodologies: Research and indigenous peoples. London: Zed Books.

Stein, Sharon, and Vanessa de Oliveira Andreotti. 2017. Decolonization in higher education, edited by M. Peters. Encyclopedia of educational philosophy and theory. Singapore: Springer.

Tamburro, Andrea. 2013. "Including decolonisation in social work education and practice." Journal of Indigenous Social Development 2(1): 1-16.

Tate, Shirley A., and Paul Bagguley. 2017. "Building the anti-racist university: Next steps." Race, Ethnicity and Education 20(3): 289-299.

Vorster, Jo-Anne, and Lynn Quin. 2017. "The 'decolonial turn': What does it mean for academic staff development?" Education as Change 21(1): 31-49.

Winfield, Brenda. 2017. "What 'decolonised education' should and shouldn't mean." The Conversation 14 February. https://theconversation.com/what-decolonised-education-should-and-shouldn'tmean-72597 (Accessed 14 September 2020).

Zembylas, Michalinos. 2018. "Decolonial possibilities in South African higher education: Reconfiguring humanising pedagogies as/with decolonising pedagogies." South African Journal of Education 38(4). https://doi.org//10.15700/saje.v38n4a1669 (Accessed 17 September 2020). 